\title{
KONSEP DAN DESAIN ROAD TRIP VIRTUAL BERBANTUAN VIDEO KOTA PEKALONGAN BERBASIS WEB
}

\author{
Dicke Junryan Saut HS, Bambang Ismanto, Nurul Amalia \\ STMIK Widya Pratama Pekalongan \\ J1. Patriot No.25 Pekalongan Jawa Tengah \\ e-mail: dicke.stmikwp@gmail.com, bams.stmikwp@gmail.com, amalia.0121@gmail.com
}

\section{RINGKASAN}

Pandemi Covid-19 membawa dampak terhadap kegiatan wisata, sosial dan budaya. Kebijakan Pemerintah yang memberlakukan pembatasan kegiatan masyarakat menyebabkan masyarakat banyak bergiatan di rumah. Bahkan untuk pulang kampung dihari besar keagamaan juga dihimbau untuk tidak dilakukan. Kegiatan yang cukup signifikan terjadi peningkatannya adalah penggunaan internet, hal ini dibuktikan dengan adanya peningkatan pembelian pulsa dan paket data di masa Pandemi. Permasalahan di atas yang menjadi trigger disusunnya Konsep dan Desain Road Trip Virtual berbantuan Video Kota Pekalongan Berbasis Web. Road Trip Virtual Berbantuan Video Kota Pekalongan berbasis Web ini akan membawa pengunjung untuk menikmati jalan-jalan protokol dan beberapa lokasi wisata di kota Pekalongan dengan seolah-olah sedang menggunakan mobil (driving tour) berkeliling di jalan-jalan protokol di Kota Pekalongan atau sedang berjalan kaki (walking tour) berkeliling di lokasi-lokasi wisata di Kota Pekalongan. Disamping itu Web Road Trip Virtual dapat digunakan untuk mempromosikan kembali Kota Pekalongan kepada masyarakat sebagai kota destinasi wisata, juga untuk menarik turis baik yang sudah pernah berkunjung ke Pekalongan, maupun yang belum pernah. Konsep dan desainnya menggunakan metode pengembangan Multimedia dan tahapan pembuatan videonya mengacu pada 3 tahapan pembuatan video yakni praproduksi, produksi dan pascaproduksi.

Kata Kunci : Konsep dan Desain, Road Trip Virtual, Kota Pekalongan, Video, Web, Pandemi Covid 19

\section{PENDAHULUAN}

Hampir seluruh belahan dunia dilanda Pandemi Covid-19 pada permulaan tahun 2020 dan berdampak pada seluruh sektor tidak terkecuali sektor pariwisata di Kota Pekalongan. Sejak awal tahun 2021 di Indonesia melaksanakan PPKM atau Pemberlakuan Pembatasan Kegiatan Masyarakat untuk mempersempit ruang gerak penyebaran efek global Covid-19 di wilayah Indonesia. Sebelumnya pemerintah juga telah menerapkan PSBB atau Pembatasan Sosial Berskala Besar yang dilaksanakan di beberapa daerah di Indonesia. PPKM berlangsung di beberapa daerah potensial terserang Covid-19 yaitu di pulau Jawa dan Bali.
Dampak dari Covid 19 dan pelaksanaan kebijakan pemerintah tersebut tentu sangat berpengaruh terhadap sektor pariwisata, sosial dan budaya. Tempat-tempat yang biasanya ramai menjadi sepi seperti kantorkantor, tempat peribadatan, pertokoan, tempat hiburan dan sekolah. Himbauan pemerintah tentang physical-distancing dan pemberlakukan work from home (WFH) mengakibatkan masyarakat lebih banyak menghabiskan waktu di rumah. Sebagai akibat dari himbauan tersebut, masyarakat akhirnya banyak berinteraksi dan bergantung pada teknologi digital salah satunya adalah menfaatkan perangkat mobile maupun komputer untuk bermain internet dari rumah. Menurut hasil survey dari Badan Pusat Statistik Kota Pekalongan, perubahan pengeluaran 
dominan masyarakat selama masa pandemi atau new normal adalah untuk pembelian bahan makanan sebegsar 53,64\% dan yang kedua adalah untuk pembelian pulsa dan paket data sebesar 19,54\% (Kurniasih, Tri Utami, dkk, 2021).

Kota Pekalongan sebagai salah satu kota tujuan wisata juga mengalami dampak penurunan jumlah wisatawan selamat masa pandemi ini. Tempat destinasi wisata yang dikelola Pemkot Pekalongan yakni Museum Batik, Pusat Informasi Mangrove (PIM), Pantai Slamaran dan Pantai Pasir Kencana juga telah tidak beroperasi mulai 16 Maret 2020 untuk mencegah penularan Covid-19. (Tim Komunikasi Publik Dinkominfo Kota Pekalongan, 2020)

Keadaan semua ini yang menjadi trigger dikembangkanya Konsep dan Desain Road Trip Virtual Berbantuan Video Kota Pekalongan berbasis Web. Road Trip Virtual Berbantuan Video Kota Pekalongan berbasis Web ini adalah aplikasi yang berjalan di platform web agar dapat diakses kapanpun dan dimanapun selama masih tersambung dengan internet. Website ini akan membawa pengunjung web untuk menikmati jalan-jalan protokol dan beberapa lokasi wisata di kota Pekalongan dengan seolah-olah sedang menggunakan mobil (driving tour) berkeliling di jalanjalan protokol di Kota Pekalongan atau sedang berjalan kaki (walking tour) berkeliling di lokasi-lokasi wisata di Kota Pekalongan. Apalagi dimasa Pandemi Covid-19 dengan adanya pembatasan kegiatan masyarakat, kegiatan berwisata maupun pulang kampung tidak dapat dilakukan. Web Road Trip Virtual dapat digunakan untuk mempromosikan kembali Kota Pekalongan kepada masyarakat sebagai kota destinasi wisata, juga untuk menarik turis baik yang sudah pernah berkunjung ke Pekalongan, maupun yang belum pernah. pengunjung dapat berwisata secara virtual atau sekedar melepas rindu dengan seolaholah berjalan-jalan di kota Pekalongan karena tidak bisa pulang kampung ke Pekalongan. Website ini sebenarnya merupakan aplikasi virtual tour. Selama masa Pandemi covid-19, Virtual Tour bisa menjadi alternatif sarana wisata (Kemenparekraf/Baparekraf RI, 2021). Dengan Virtual Tour memungkinkan pengguna berada di lingkungan yang sebenarnya, dan memiliki interaksi dengan lingkungan sekitarnya (Hamid, H. Wee dan Asri 2016). Virtual tour telah banyak digunakan sebagai sarana promosi yang efektif khususnya dibidang pariwisata melalui media interaktif (Fitri, 2016).

Road Trip Virtual Berbantuan Video Kota Pekalongan berbasis Web ini tidak menggunakan foto panorama 360 derajat dalam konten tournya, tetapi menggunakan video. Video adalah salah satu elemen multimedia yang menarik dimana membawa pengguna komputer seolah ke dunia nyata (Vaughan, 2011: 164). Terdapat 3 tahapan untuk pembuatan video, yaitu praproduksi, produksi, dan pasca produksi (Wiratna, Rahmatsyam, 2017). PraProduksi biasanya dihubungkan dengan tahap persiapan untuk pembuatan video. Terdapat beberapa tahapan dalam PraProduksi yang biasanya dilakukan oleh Tim Pembuat Video. Produksi, Untuk mendukung pengambilan gambar, diperlukan Storyboard yang akan digunakan sebagai background event sehingga mendukung storyline yang digunakan. Pengambilan gambar dilaksanakan sesuai storyboard yang telah dibuat. Secara umum tahap pasca produksi adalah proses penyuntingan yang meliputi penggabungan sumber video dan gambar serta penambahan elemen lain (efek visual dan efek musik).

Sebagai sarana alternatif, dengan menggunakan website ini diharapkan 


\section{METODE PENELITIAN}

Untuk menyusun dan menyelesaikan Konsep dan Desain Road Trip Virtual Berbantuan Video Kota Pekalongan berbasis Web ini, dilakukan dengan tahapan menyusun konsep dan desain, dimana 2 tahapan ini adalah bagian dari Metode Pengembangan Multimedia yang memiliki 6 tahapan yakni ; Konsep, Desain, Pengumpulan Bahan, Pembuatan, Pengujian dan Distribusi (Binanto, 2010). Sedangkan untuk pembuatan video dilakukan dengan 3 tahap yakni : praproduksi, produksi dan pasca produksi.

\section{PEMBAHASAN}

Berikut adalah pembahasan tentang Konsep dan Desain Road Trip Virtual Berbantuan Video Kota Pekalongan berbasis Web.

\section{Konsep}

Gambaran Umum Aplikasi. Jenis Aplikasi ini termasuk aplikasi Virtual Tour interaktif berbasis web, hanya saja tidak menggunakan foto panorama 360 derajat dalam konten tournya, tetapi menggunakan video yang telah direkam dengan kamera sehingga lebih menimbulkan suasana yang nyata. Video berisi suasana di perjalanan melewati tempat-tempat tertentu yang bisa dipilih oleh pengguna aplikasi. Ada 2 kelompok video yang bisa dipilih, video perjalanan dengan mobil (driving tour) dan video perjalanan dengan jalan kaki (walking tour). Di dalam video, tidak hanya visual di balik setir mobil, pengguna juga bisa melihat pemandangan dan mendengarkan ramainya suara dan suasana jalan-jalan protokol di Kota Pekalongan.

Kelompok video dengan visual grafis dari balik setir kemudi mobil (driving tour) terdiri dari video perjalanan melewati tempat tempat tertentu di Kota Pekalongan. Seperti melewati Grosir Batik Setono, Kawasan Kanzus Sholawat Habib Lutfi, Alun-Alun Kota, Alun-alun Kawasan Jetayu, LP Panjang, Pantai Ngeboom,
Makam Pahlawan, Simpang 5, Pecinan, Monumen, Lapangan Mataran, Kantor Pemkot. Pekalongan.

Titik awal perjalanan yang bisa dipilih oleh pengguna ada 3 titik. Pertama dari Timur Kota Pekalongan tepatnya dari jalan Dr, Sutomo di depan Terminal Kota Pekalongan, Kedua dari Pintu Exit Tol Kota Pekalongan dan yang ketiga adalah dari Barat Kota Pekalongan tetapnya dari Jalan Gajah Mada di depan Stasiun Kota Pekalongan.

Kelompok video dengan visual grafis berjalan kaki (walking tour) terdiri dari video yang berisi suasana kawasan tertentu di Kota Pekalongan seperti Kawasan Budaya Jetayu, Alun-Alun Kota Pekalongan, Lapangan Mataram, kampung batik dan lain-lain.

Aplikasi ini juga dilengkapi fasilitas tambah dan hapus file video oleh pengelola web dengan terlebih dahulu login ke fasilitas tersebut.

Tujuan Pengembangan Aplikasi ini adalah agar Kota Pekalongan memiliki aplikasi yang dapat memberikan gambaran tentang suasana di Kota Pekalongan seperti suasana di jalan-jalan protokol, suasana di kawasan budaya, Kawasan Pecinan, wisata Religi, Wisata Kuliner, Perkampungan dan Grosir Batik dan lain sebagainya ada di Kota Pekalongan. Dengan Aplikasi ini juga diharapkan dapat menjadi tuntunan jalan para wisatawan menuju tempat-tempat tertentu di Kota Pekalongan. Melalui aplikasi ini,pengguna bisa merasakan pengalaman seperti menyetir maupun berjalan kaki keliling ketempat-tempat yang telah disebutkan di atas.

Pengguna aplikasi ini ditujukan kepada perantau yang rindu suasana di Kota Pekalongan dan tentunya para wisatawan yang rindu jalan-jalan keliling kota. Melalui Aplikasi ini perantau maupun 
wisatawan masih bisa wisata virtual ke kota Pekalongan walaupun dalam masa PPKM.

\section{Desain}

\section{Desain Struktur Menu}

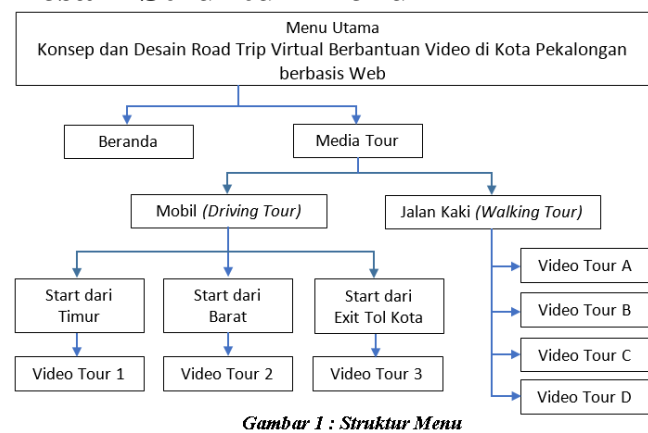

\section{Keterangan :}

Video Tour 1 (driving tour) dengan rute sbb :

Terminal Bis Kota $\rightarrow$ Grosir Batik Setono $\rightarrow$ Kawasan Kanzus Sholawat Habib Lutfi $\rightarrow$ Alun-Alun Kota $\rightarrow$ Alun-alun Kawasan Jetayu $\rightarrow$ LP Panjang $\rightarrow$ Pantai Ngeboom $\rightarrow$ IAIN $\rightarrow$ Simpang $5 \rightarrow \mathrm{Jl}$. Manggis $\rightarrow \mathrm{Jl}$. Belimbing $\rightarrow$ Alun-Alun Jetayu $\rightarrow$ Polres Kota $\rightarrow$ Monumen $\rightarrow$ Lapangan Mataran $\rightarrow$ Kantor Pemkot.

Video Tour 2 (driving tour) dengan rute sbb :

Stasiun KA $\rightarrow$ Monumen $\rightarrow$ Jl. Slamet $\rightarrow$ Lapangan Mataram $\rightarrow$ Jl. Argopuro $\rightarrow$ Jl. Mansyur $\rightarrow$ Jl. Sudirman $\rightarrow$ Kawasan Religi Makam Habib Ahmad $\rightarrow$ Jl. Sulawesi $\rightarrow$ Jl. Hayam Wuruk $\rightarrow$ Jl. Hasannudin $\rightarrow$ Jl. Sultan Agung $\rightarrow$ Lapangan Jetayu $\rightarrow$ Makam Pahlawan $\rightarrow$ Pantai Ngeboom

Video Tour 3 (driving tour) dengan rute sbb :

Exit Tol Kota $\rightarrow$ Grosir Batik Setono $\rightarrow$ Kawasan Kanzus Sholawat Habib Lutfi $\rightarrow$ Alun-Alun Kota $\rightarrow$ Alun-alun Kawasan Jetayu $\rightarrow$ LP Panjang $\rightarrow$ Pantai Ngeboom $\rightarrow$ IAIN $\rightarrow$ Simpang $5 \rightarrow$ PLN $\rightarrow$ Pecinan $\rightarrow$ Alun-Alun Jetayu $\rightarrow$ Polres Kota $\rightarrow$ Monumen $\rightarrow$ Lapangan Mataran $\rightarrow$ Kantor Pemkot. Pekalongan
Video Tour A (walking tour) : Keliling di Alun-Alun Kota

Video Tour B (walking tour) : Keliling di Kawasan Budaya Jetayu

Video Tour C (walking tour) : Keliling di Lapangan Mataram - Pasar Tiban

Video Tour D (walking tour) : Keliling di Kampung Batik Kauman dan Pesindon

\section{Arsitektur Sistem}

Berikut adalah penggambaran secara garis besar kerja sistem yang digambarkan melalui pemodelan yang saling berinteraksi satu dan lainnya. Pada arsitektur sistem ini menggambarkan pada sistem tentang komponen-komponen yang ada. Aplikasi berbasis website yang dirancang ini mempunyai dua kelompok pengguna yakni pengunjung dan administrator atau pengelola web.

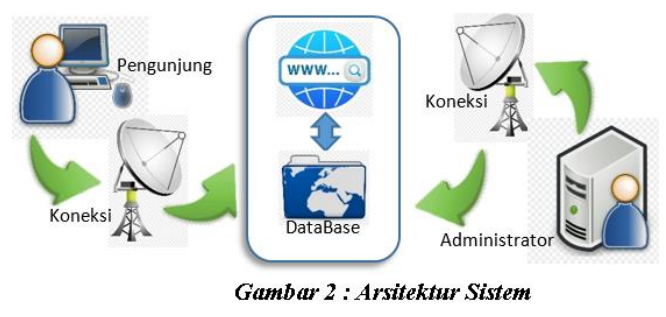

3. Desain Layar Tampilan

a. Layar Kerja Tampilan Menu Utama

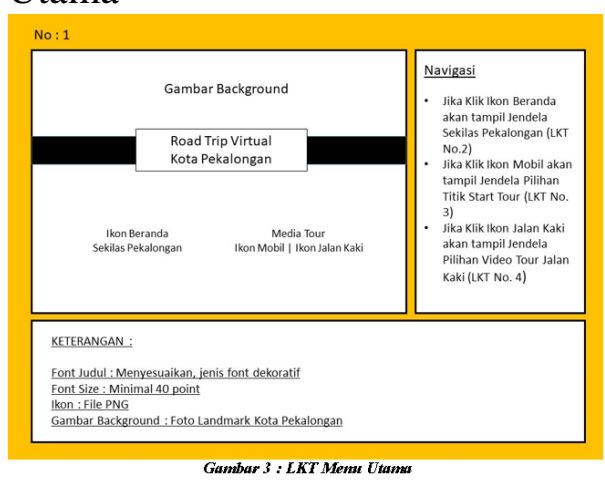


b. Layar Kerja Tampilan Beranda

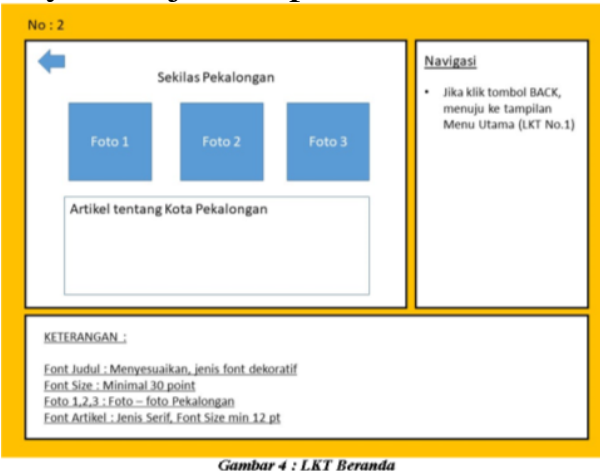

c. Layar Kerja Tampilan Menu Start Tour

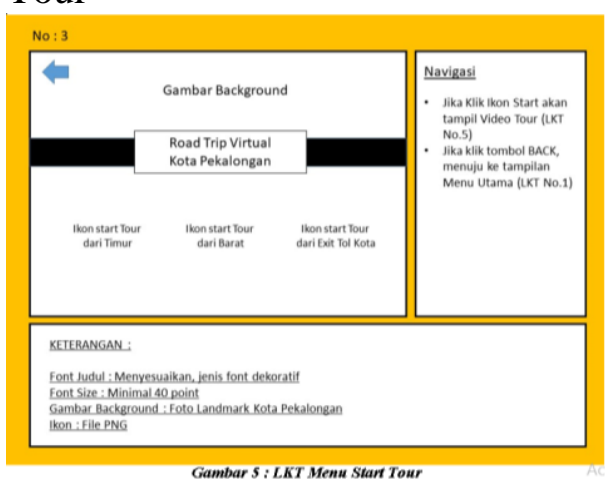

d. Layar Kerja Tampilan Menu Video Tour Jalan Kaki

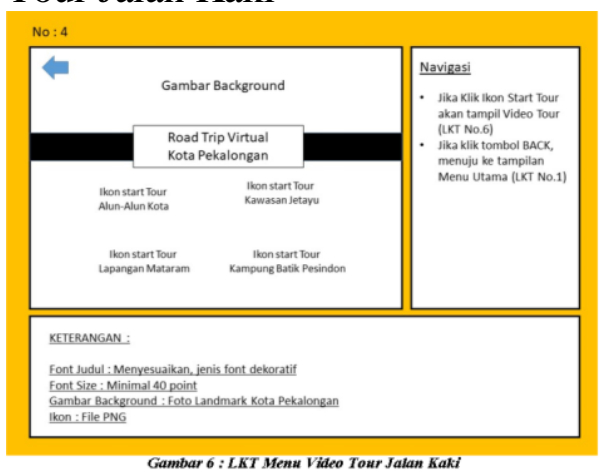

e. Layar Kerja Tampilan Display Video Tour dengan Mobil

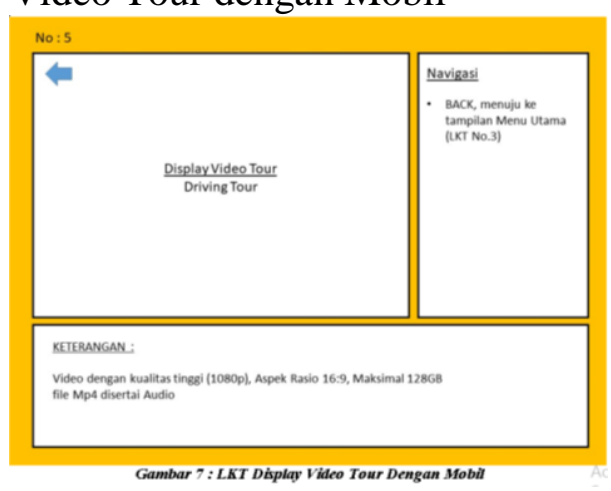

f. Layar Kerja Tampilan Display Video Tour dengan Jalan Kaki

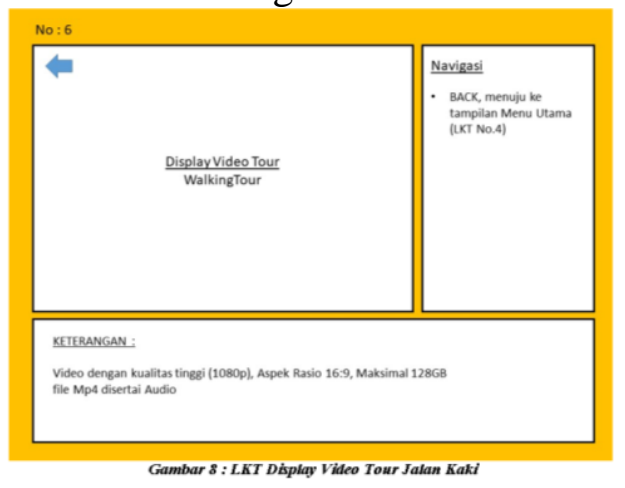

g. Layar Kerja Tampilan Login Administrator

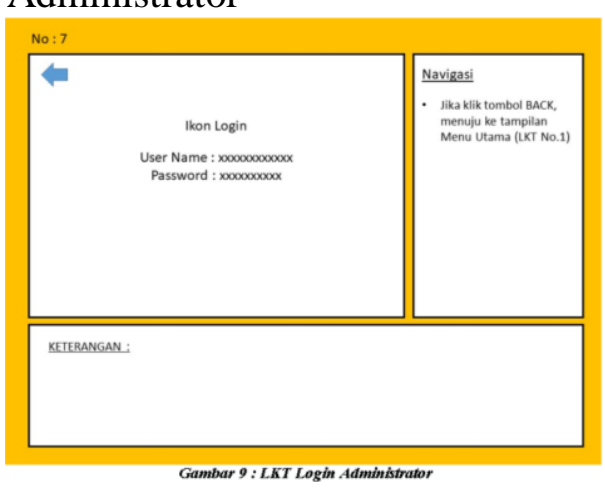

\section{Tahapan Pembuatan Video}

a. Pra Produksi

Pengembangan ide

Video yang dibuat terdiri dari 2 mode pengambilan, pertama perekaman dengan menempatkan posisi kamera di dashboard mobil dan yang kedua kamera dibawa petugas perekam video sambil berjalan pada kawasan tertentu.

Mode perekaman video dari dashboard mobil (driving tour).

Perekaman dilakukan dengan mobil berjalan dengan kecepatan wajar maksimal $60 \mathrm{~km} / \mathrm{jam}$ untuk 3 rute dan suara kebisingan di jalan agar ikut direkam :

\section{Rute 1 :}

Terminal Bis Kota $\rightarrow$ Grosir Batik Setono $\rightarrow$ Kawasan Kanzus Sholawat Habib Lutfi $\rightarrow$ AlunAlun Kota $\rightarrow$ Alun-alun Kawasan Jetayu $\rightarrow$ LP Panjang $\rightarrow$ Pantai 
Ngeboom $\rightarrow$ Makam Pahlawan $\rightarrow$ Simpang $5 \rightarrow \mathrm{Jl}$. Menggis $\rightarrow \mathrm{Jl}$. Blimbing $\rightarrow$ Alun-Alun Jetayu $\rightarrow$ Polres Kota $\rightarrow$ Monumen $\rightarrow$ Lapangan Mataran $\rightarrow$ Kantor Pemkot. Pekalongan

\section{Rute 2 :}

Stasiun KA $\rightarrow$ Monumen $\rightarrow \mathrm{Jl}$. Slamet $\rightarrow$ Lapangan Mataram $\rightarrow$ $\mathrm{Jl}$. Argopuro $\rightarrow \mathrm{Jl}$. Mansyur $\rightarrow \mathrm{Jl}$. Sudirman $\rightarrow$ Kawasan Religi Makam Habib Ahmad $\rightarrow \mathrm{Jl}$. Sulawesi $\rightarrow$ Jl. Hayam Wuruk $\rightarrow$ Jl. Hasannudin $\rightarrow$ Jl. Sultan Agung $\rightarrow$ Lapangan Jetayu $\rightarrow$ Makam Pahlawan $\rightarrow$ Pantai Ngeboom

\section{Rute 3 :}

Exit Tol Kota $\rightarrow$ Grosir Batik Setono $\rightarrow$ Kawasan Kanzus Sholawat Habib Lutfi $\rightarrow$ AlunAlun Kota $\rightarrow$ Alun-alun Kawasan Jetayu $\rightarrow$ LP Panjang $\rightarrow$ Pantai Ngeboom $\rightarrow$ Makam Pahlawan $\rightarrow$ Simpang $5 \rightarrow \mathrm{Jl}$. Manggis $\rightarrow \mathrm{Jl}$. Blimbing $\rightarrow$ Alun-Alun Jetayu $\rightarrow$ Polres Kota $\rightarrow$ Monumen $\rightarrow$ Lapangan Mataran $\rightarrow$ Kantor Pemkot. Pekalongan

Mode perekaman video sambil berjalan kaki (walking tour).

Perekaman dilakukan dengan dengan berjalan kaki dengan kecepatan wajar berjalan kaki untuk 4 rute dan suara kebisingan di jalan agar ikut direkam :

Rute 1 : Keliling di Alun-Alun Kota

Rute 2 : Keliling di Kawasan Budaya Jetayu

Rute 3 : Keliling di Lapangan Mataram - Pasar Tiban

Rute 4 : Keliling di Kampung Batik Kauman dan Pesindon

Perencanaan Pelaksanaan :

Pelaksanaan Perekaman Video dapat dilakukan pada saat siang hari dengan cahaya yang cukup terang dan cuaca yang cerah, antara pukul 08.30 WIB - 15.00 WIB.

Perkiraan jumlah hari pengambilan gambar : kurang lebih 7 hari

\section{Storyboard}

Storyboard Video Rute 1(driving tour) :

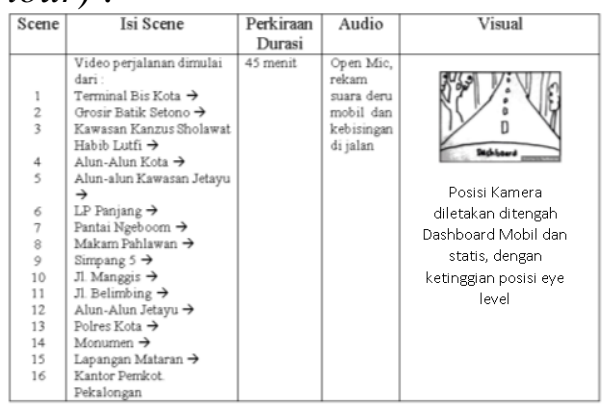

Storyboard Video Rute 2 (driving

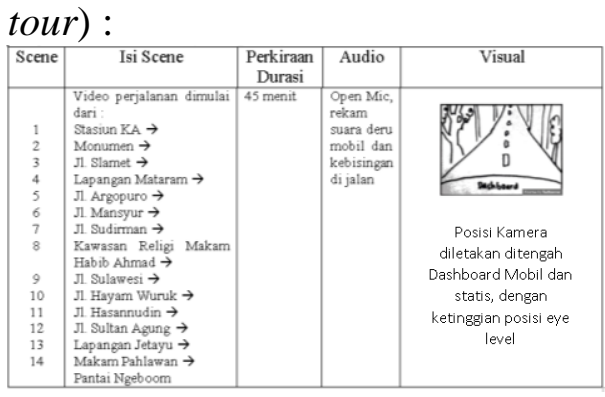

Storyboard Video Rute 3 (driving tour) :

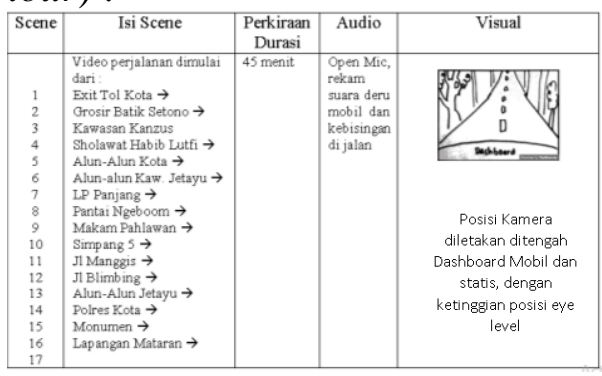

Storyboard Video Rute 1 (Walking tour) :

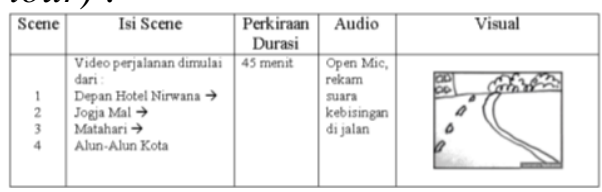


Storyboard Video Rute 2 (Walking

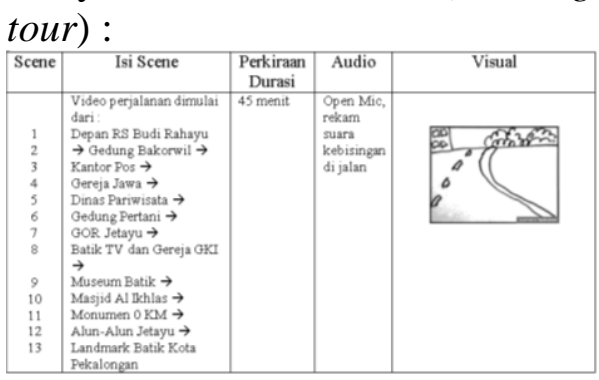

Storyboard Video Rute 3 (Walking tour) :

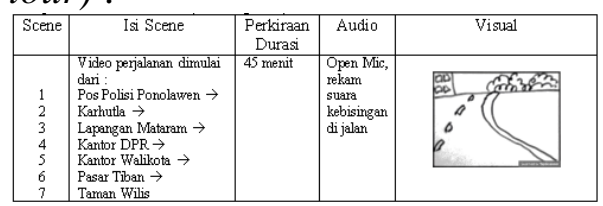

Storyboard Video Rute 4 (Walking tour) :

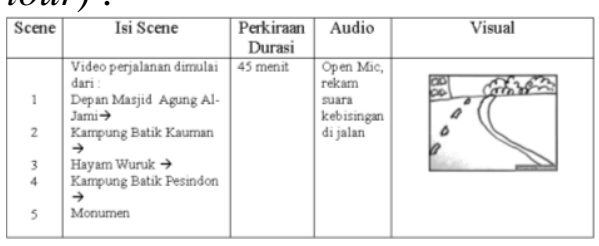

b. Produksi

Tahap Produksi dimulai dari menggunakan alat perekam untuk merekam video baik secara visual maupun audio berdasarkan naskah dan konsep yang telah direncanakan dari awal.

Pada proses produksi yang perlu disiapkan :

1) Komputer atau laptop

2) Kamera, handphone atau webcamera

3) Penampil video

4) $\mathrm{Mic}$

5) Stabilizer kamera

6) Tripod

7) Mobil

Pada saat perekaman video dengan kamera, karena gambar yang direkam adalah suasana jalan, keramaian serta suara kebisingannya maka beberapa hal yang diperhatikan :

1) Menghindari teknik Zoom

2) Audio direkam menggunakan micropone, sehingga tim dilarang berbicara saat pengambilan gambar

3) Kamera dibuat statis mengikuti gerak mobil atau orang berjalan, tanpa menggunakan teknik Panning (teknik menyuting gambar bergerak secara horizontal) ataupun Tilting (teknik menyuting gambar bergerak secara vertikal).

4) Menyuting gambar suatu objek dilakukan di posisi Eye Level, yaitu sudut penyutingan gambar sejajar dengan objek. Hasilnya menunjukkan eye catch seseorang dan teknik ini tidak memberikan kesan dramatis melainkan kesan natural.

5) Ukuran gambar perekaman yang digunakan adalah Medium Long Shot (MLS): gambar diambil dari jarak yang wajar, jadi jika misalnya ada 3 objek, semuanya akan terlihat. Jika objeknya adalah satu orang, itu terlihat dari kepala hingga lutut.

6) The Secret of Foreground Framing Shot : mengambil objek yang berada di depan background sehingga menjadi perpaduan pemandangan.

\section{c. Pasca Produksi}

Tahap pasca produksi, dilakukan penyuntingan terhadap video. Menggunakan software editing video seperti Adobe Premire atau yang lainnya. Hasil produksi pada tahap sebelumnya, tidak terlalu banyak yang harus di edit pada tahap pasca produksi. Hanya memotong frame bagian awal dan akhir video jika dibutuhkan. Jika terjadi penggabungkan 2 video atau lebih agar jalannya video tidak terlihat putus di variasi dengan efek transisi. Perlu diperhatikan pula 
kontras warna dan volume video, agar gambar dan suara di video menjadi jernih dan lebih baik. Kecepatan video disesuaikan agar durasi video tidak melebihi target yaitu minimal 30 menit dan maksimal 1 jam. File akhir video merupakan hasil render dengan format Mpeg-4, dengan resolusi maksimal 1080p agar tetap bisa berjalan di media internet.

\section{KESIMPULAN}

Road Trip Virtual Berbantuan Video Kota Pekalongan berbasis Web ini adalah aplikasi yang berjalan di platform web agar dapat diakses kapanpun dan dimanapun selama masih tersambung dengan internet. Website ini akan membawa pengunjung web untuk menikmati jalan-jalan protokol dan beberapa lokasi wisata di kota Pekalongan dengan seolah-olah sedang menggunakan mobil (driving tour) berkeliling di jalan-jalan protokol di Kota Pekalongan atau sedang berjalan kaki (walking tour) berkeliling di lokasi-lokasi wisata di Kota Pekalongan.

Di dalam video, tidak hanya visual di balik setir mobil, pengguna juga bisa melihat pemandangan dan mendengarkan ramainya suara dan suasana jalan-jalan protokol di Kota Pekalongan. Web Road Trip Virtual dapat digunakan untuk mempromosikan kembali Kota Pekalongan kepada masyarakat sebagai kota destinasi wisata, juga untuk menarik menarik turis baik yang sudah pernah berkunjung ke Pekalongan, maupun yang belum pernah.

Untuk menyusun dan menyelesaikan Konsep dan Desain Road Trip Virtual Berbantuan Video Kota Pekalongan berbasis Web ini, dilakukan dengan tahapan menyusun konsep dan desain, dimana 2 tahapan ini adalah bagian dari Metode Pengembangan Multimedia yang memiliki 6 tahapan yakni ; Konsep, Desain, Pengumpulan Bahan, Pembuatan,
Pengujian dan Distribusi. Untuk pembuatan videonya menggunakan tahapan pembuatan video ; praproduksi, produksi dan pascaproduksi.

Terdapat 3 pilihan dalam menu utama untuk memulai road trip virtual. Pertama dari Timur Kota Pekalongan tepatnya dari jalan Dr, Sutomo di depan Terminal Kota Pekalongan, Kedua dari Pintu Exit Tol Kota Pekalongan dan yang ketiga adalah dari Barat Kota Pekalongan tetapnya dari Jalan Gajah Mada di depan Stasiun Kota Pekalongan.

Kelompok video dengan visual grafis berjalan kaki (walking tour) terdiri dari video yang berisi suasana kawasan tertentu di Kota Pekalongan seperti Kawasan Budaya Jetayu, Alun-Alun Kota Pekalongan, Lapangan Mataram, kampung batik dan lain-lain.

Tujuan Pengembangan Aplikasi ini adalah agar Kota Pekalongan memiliki aplikasi yang dapat memberikan gambaran tentang suasana di Kota Pekalongan seperti suasana di jalan-jalan protokol, suasana di kawasan budaya, Kawasan Pecinan, wisata Religi, Wisata Kuliner, Perkampungan dan Grosir Batik dan lain sebagainya ada di Kota Pekalongan. Pengguna aplikasi ini ditujukan kepada perantau yang rindu suasana di Kota Pekalongan dan tentunya para wisatawan yang ingin jalan-jalan keliling kota.

Diharapkan untuk tahap selanjutnya adalah mengimplementasikan hasil konsep dan desain ini agar dapat segera digunakan oleh para pengguna dan untuk menginformasikan Kota Pekalongan dan potensi wisatanya. 


\section{DAFTAR PUSTAKA}

Ashshiddiqie, Muhammad Farhan., Premaswari, I Gusti Agung Ayu Pramidewi. (2021). Tur Wisata Virtual Bali Pada Era Society 5.0 (Bali Virtual Tourism Tour In Society 5.0 Era). Seminar Nasional Desain SANDI 2021. Volume 1 Tahun 2021.

Azani Cempaka Sari, (2018). Virtual Reality. di ambil kembali dari https://socs.binus.ac.id/2018/11/29/v irtual-reality/, di akses pada 15 Oktober 2021 Pukul 18.33 WITA.

Bakre, Namrata, Aditi Deshmukh and Prof. Yogesh Doulatramani Pavitra Sapaliga. ( 2017). "Campus Virtual Tour." Internasional Journal of Advenced Research Compututer Engineering Technology (IJARCET) 6(4): 444-448.

Binanto, Iwan. (2010). Multimedia DigitalDasar Teori dan Pengembangannya. Yogyakarta: Andi Offset.

Binanto, Iwan. (2015). Tinjauan Metode Pengembangan Perangkat Lunak Multimedia Yang Sesuai Untuk Mahasiswa Tugas Akhir. Seminar Nasional Rekayasa Komputer dan Aplikasinya 2015 ISBN: 978-60271695-1-7

CNN Indonesia, (2020). 'Road Trip' Virtual Keliling Puluhan Kota Wisata di Dunia.

https://www.cnnindonesia.com/gayahidup/20200514135320-269-

503351/road-trip-virtual-kelilingpuluhan-kota-wisata-di-dunia, Diakses pada tanggal 15 September pukul 21.20 WIB.

Dwi Prasetya, Didik. (2015). Aplikasi Virtual Tour Sebagai Media Promosi Pariwisata. https://www.researchgate.net/publica
tion/317082651_Aplikasi_Virtual_T our_Berbasis_Web_Sebagai_Media_ Promosi_Pariwisata?enrichId=rgreq56a915ad8d439af7de57ccfdfbad749 $2-$

XXX\&enrichSource $=$ Y292ZXJQY WdlOzMxNzA4MjY1MTtBUzo2Mj cxMDYyNjY1MDkzMTNAMTUyN jUyNTE5MzY2NQ\%3D\%3D\&el=1 _x_3\&_esc=publicationCoverPdf, Diakses pada 5 September 2021 Pukul 21.20 WIB.

Dwi Winata, Ferry., Mutiarin, Dyah. (2021). Inovasi Ekowisata Digital Saat Pandemi Covid-19 Studi Kasus: Virtual Experience Oleh Sebumi.Id. Jurnal Muara Ilmu Sosial, Humaniora, dan Seni, Vol. 5, No. 1, April 2021: hlm 164-169.

Fitri, Mega Orina. (2016). "Rancang Bangun Aplikasi Virtual Tour Monumen Mandala Berbasis Android." Jurnal Informatika Sains dan Teknologi 1(1).

Hamid, Z.A., M.H. Hanafiah H. Wee, dan N.A.A. Asri. (2016). "The effect of social media on tourists' decision to travel to Islamic destination: A case of Malaysia." Heritage, Culture and Society - Radzi et al. (Eds). London: Taylor \& Francis Group, London, 501-505.

Kemenparekraf/Baparekraf RI, (2021). Virtual Tour sebagai alternatif Berwisata di Tengah Pandemi Covid19.

https://kemenparekraf.go.id/ragampariwisata/Virtual-Tour\%2CAlternatif-Berwisata-di-TengahPandemi-COVID_19, diakses pada 2 Nopember 2021 Pukul 11.25 WIB)

Kurniasih, Nurul., Tri Utama, Dinar., dkk. (2021). Profil Masyarakat Kota Pekalongan di Era New Normal, 
Analsis Hasil Survei Sosial Ekonomi Dampak Covid-19. Pekalongan : Badan Pusat Statistik

Puji Lestari, Wahyu., Buchori,Achmad., Indriati Wardani, Theodora. (2020). Perancangan Sistem Aplikasi Wisata Di Kabupaten Blora Menggunakan Virtual Tour, JIPETIK: Jurnal Ilmiah Penelitian Teknologi Informasi \& Komputer, Vol. 1, No. 1, Juni 2020, Hal. 13-20 .

Sukaesih, Siti Khadijah, Ute Lies., dkk. (2020). Wisata Virtual Pada Perpustakaan Digital Selama Masa Pandemi Covid-19. Tornare - Journal of Sustainable Tourism Research. Vol. 2, No. 3, September 2020: 63 77.

Surjono, Herman Dwi. (2014). Pengantar Video. Naskah Publikasi. Yogyakarta: Universitas Negeri Yogyakarta.
Tim Komunikasi Publik Dinkominfo Kota Pekalongan, (2020). Tak Ada PHK Pegawai di Lingkup Sektor Pariwisata Kota Pekalongan. (https://batiktv.pekalongankota.go.id /berita/tak-ada-phk-pegawai-dilingkup-sektor-pariwisata-kotapekalongan.html, diakses pada 2 Nopember 2021 Pukul 09.35 WIB)

Vaughan. T. (2011). Multimedia : Making it Works (8th Edition). New York: McGraw-Hill.

Wiratna, Haris dan Lakoro, Rahmatsyam (2017). Video promosi wisata pantai kabupaten jember dengan konsep sinematik. Jurnal sains dan seni ITS, 2. 94-99

Wong, Yue-Ling. (2009). Digital Media Primer Digital Audio, Video, Imaging, and Multimedia Programming. New York: Pearson Education. 